\title{
A Case Study on Service Design in an Egyptian Professional Consulting Firm
}

\author{
Sanetake Nagayoshi \\ Department of Industrial Engineering and Management, Graduate School of Decision Science and \\ Technology, Tokyo Institute of Technology, Tokyo, Japan \\ Correspondence should be addressed to: Sanetake Nagayoshi; nagayoshi.s.aa@m.titech.ac.jp
}

Received 8 February 2013; Accepted 27 February 2013; Published 28 July 2013

Copyright (C) 2013 Sanetake Nagayoshi. Distributed under Creative Commons CC-BY 3.0

\begin{abstract}
Organizational change and transformation traditionally attracts many researchers to dedicate their times and energy to research, because it is one of the important research topics. However there does not seem to be enough research especially in Arab world such as Egypt, although the area is one of the significant regions now. In this paper, author discusses three topics based upon a case study at a professional consulting firm in Egypt which is specialized in Kaizen -continuous improvement. (1) How did the firm acquire the know-how knowledge about Kaizen? , (2) How did the customer of the consulting firm succeed in the QC Circle activities with the support of the firm? , (3) What are the key factors for success both in of the firm and their customers? At the result, it is supposed that the learning process at the firm could be interpreted with SECI model, and the innovative transformation process in their customers could be interpreted by applying five Stages model (Liu, Nagayoshi and Iijima; 2012). Also the key success factors for Kaizen could be localization of Kaizen activities. The generalizability of these findings can be ascertained with more studies in future.
\end{abstract}

Keywords: Service design; professional consulting firm; Kaizen; success factors.

\section{Introduction}

Organizational change and transformation is an important research topic that has attracted the attention of many researchers and practitioners in organization research. Traditionally, organizational change and transformation mainly focuses on the change in organizations' structures and practices. However, as organizations increasingly face changes in the economical, geopolitical, contextual, and technological aspects, discourses on organizational transformation has begun to draw from many other disciplines and various perspectives.

The geopolitical and economical context of the Arab world during the twentieth century precipitated several predicaments and constraints in the business arena. These constraints negatively influenced the growth of strong and agile business environment capable of sustaining local enterprises to compete outside the sphere of their traditional geographic influence. In addressing the business landscape in this

Cite this Article as: Sanetake Nagayoshi (2013), "A Case Study on Service Design in an Egyptian Professional Consulting Firm," IBIMA Business Review, Vol. 2013 (2013), Article ID 193087, DOI: 10.5171/2013. 193087 
context, it is said that business organizations evolved in most Arab societies as fundamentally trading or service organizations. Very few countries in this region, particularly in the mostly populated states, developed some form of productive enterprises. These enterprises lacked innovative processes and were generally satisfying the meager needs of largely unsophisticated, non-complaining consumer communities.

Especially in Egypt, there are, however, favorable conditions such as population increase and industry diversification. According to World Health Statistics (World Health Organization, 2012), the population in Egypt is 81,121 thousands in 2010, the annual population growth rate from 2000 to 2010 is $1.8 \%$ the total fertility rate per woman in 2010 is 2.7. Egypt succeeded industry diversification unlike other Arab countries which rely on oil and/or financial industry in Gulf area. There are multiple industries such as primary products, food processing, textile, petroleum products, heavy industries, other manufacturing, tradable services, other services like sea trade and transportation based on geographical favorable conditions such as Nile River and Suez Canal (Dessus and Eiseman, 1998). Actually Egypt is listed on the NEXT11, which are expected to develop near future. The World Bank (2013) mentioned that Gross Domestic Products in Egypt is 229.5 billion USD in 2012 . However there were some difficulties for industry these days, such as the revolution with governmental change in 2011, the election with rude demonstration from 2011 to 2012 and political fluctuation with rude demonstration in 2012-2013, and so on. These circumstances could lead bad impact to the industries in Egypt. For recovering from the unfavorable situation in the economy, it is assumed that it is one of the important initiatives for each company to make an attempt with business process improvement like Kaizen.
In this paper, author discusses service design in Egyptian professional consulting firm named "Productivity and Quality Improvement Center" in Cairo, which supports Egyptian manufacturing companies to improve the business process, productivity and profitability. And then it is supposed what key success factors are for the professional firm to support business process improvement.

The remainder of the paper is organized as follows: First, related literatures are reviewed in section 2. After that relative research method is introduced in section 3 . Next, an attempt of a certain professional firm is introduced in section 4 . Then, the cases are analyzed in section 5. Some additional findings are discussed in section 6 . Finally, the limitations of this study and implications for future research are described in section 7 .

\section{Literature Review}

\section{A. Kaizen Activity}

The basis of operations that efficiently secure quality is to develop a best standard to accomplish it, and to work according to it. However as product varieties increased and product life cycles become shorter, it became impossible to follow this change by just working according to the standard. Then, organizational Kaizen initiatives on the basis of the standard, as Plan-Do-Check-Action, were invented in the manufacturing company in Japan (Deming, 1996; Florida, 2005; Enkawa, 2009; Enkawa, 2010). Enkawa (2010) mentioned that the meaning of Kaizen is incremental improvement or continuous improvement.

QCC (Quality Control Circle) activities are small-group activities which are performed by those working on-site at worksites that continuously perform quality management and kaizen. QC Circle activities were originally invented mainly at manufacturing 
industry in Japan, however QC Circle activities outside Japan are practiced in broader industries and institutions than Japan, and the broadly conceived quality circle concepts are beginning to be applied (Ayano, 2009). The strengths and weakness in Japanese manufacturing industry come from Japan's indigenous culture which involves high uncertainty avoidance for objects and time, and is quite different from not only Western countries but also other Asian countries (Enkawa, 2010).

\section{B. Organization Learning}

Enterprise transformation is related to organization learning, which is a process of detecting and correcting errors (Fiol and Lyles, 1985) to improve an organization's value creation capabilities.

Other knowledge management processes such as SECI (Nonaka and Takeuchi, 1995), along with cultural changes and structural changes, can increase an enterprise's "readiness for transformation". They are therefore likely to enable a successful transformation.

Slater and Narver (1995) described the processes through which organizations develop and use new knowledge to improve performance.

Liu, Nagayoshi and Iijima (2012) discussed how enterprise transformation, business process change, and organization learning affect each other. They identified "readiness" to be an important factor for successful enterprise transformation. This factor could be affected by organization learning, organizational culture, and organizational structure. Liu, Nagayoshi and Iijima (2012) also provided a promising way of analyzing enterprise transformation or innovationrelated problems at the ontological level from an engineering perspective, which can greatly reduce the complexity of problems while significantly enhancing effectiveness and efficiency.

\section{C.Capacity Development in Developing Countries}

Productivity and Quality Improvement Center in Cairo was established with support by Japan International Corporation Agency.

Capacity Development is one of the ideas for the corporation in developing countries, the essential policy of which is that corporation for developing countries should aim at improving their own capability for solving the issues, and the characteristics of which are 1) supporting their spontaneous motivation such as solving their own issue, 2) targeting at improving not only individual and organizational capability but also social system and circumstances behind the issue (Mabuchi and Kuwajima,2004; Honda and Noguchi,2004).

To our best knowledge, very few countries in Arab world, including Egypt, developed some form of productive enterprises. These enterprises lacked innovative processes and were generally satisfying the meager needs of largely unsophisticated, non-complaining consumer communities.

In this sense, author is interested in three research topics; 1) How did the Egyptian professional firm acquire the know-how Knowledge? , 2) How did the customer of the professional firm succeed in the QC Circle activities with the professional firm's support? , 3) What are the key factors for success both in the professional firm and their customer?

\section{Research Method}

Author employed the case study method (Eisenhardt, 1989) and studied a single case. The case study was based on four interviews with three managers in Productivity Improvement Center at Cairo in Egypt, their presentation in a certain seminar and several documents such as the brochure, presentation materials and consulting tools. Especially the interview which were 
conducted from March to November 2012, as follows;

- The First Interview: Executive Manager;

- The Second Interview: Executive Manager;

- The Third Interview: Executive Manager, Head of Training Section and Head of Consulting Section

- The Fourth Interview: Head of Consulting Section.

Each interview lasted for 1 to 3 hours. The interviews are analyzed and the results are described in the following sections. To ensure the accuracy of interpretations, the results were reviewed by the manager of Productivity and Quality Improvement Center.

\section{Case Study}

Author conducts the case study by applying Productivity and Quality Improvement Center at Cairo in Egypt.

\section{A. Company Description}

Productivity and Quality Improvement Center began their activities officially in February 2006 as one of the technical centers under the technological development sector, Ministry of Trade and Industry in collaboration with Japan International Corporation Agency, for strengthening the quality and productivity systems in Egyptian factories in the framework of the Egyptian Industrial Modernization Program. Productivity and Quality Improvement Center is responsible for upgrading quality culture and activities in Egypt for both production and services sectors to develop and modernize these activities to comply with the international standards.

The mission of Productivity and Quality Improvement Center are 1)Driving productivity enhancement by waste reduction, 2)Increase efficiency and effectiveness of employees, 3)Activate quality management systems, and 4)Transferring the Japanese Problem solving techniques based on Kaizen methodology to Egyptian companies.

\section{B. Services}

Productivity and Quality Improvement Center provides training courses, workshops and consulting services to explain and install the principles of Japanese kaizen methodology, which aim at increasing productivity, reducing waste of time and raising the efficiency levels of performance for both of machines and workers to achieve an integrated system in accordance with the modern foundations of production.

Productivity and Quality Improvement Center provides five packaged training courses such as Kaizen system and customer satisfaction, Quality Assurance, Basic Quality Control Seven Tools and the new QC 7 tools, Total Quality Management (TQM), Just In Time System, Total Productive maintenance (TPM) and Industrial Engineering, however they are often modified based on the customer's requests. And consulting service is also provided. It supports Egyptian companies in the field of application of quality systems, improve productivity and reduce wastes such as 1) Defects, 2) Process, 3) Waiting Time, 4)Worker's Motion, 5)Transportation, 6)Inventory ,and 7)Overproduction. In the consulting service, it sets a time table for improving system's quality and productivity in the factory including human issues, machinery issues, material issues, and methodological issues to increase the visibility of productivity and quality.

\section{Service for Egyptian Carpet Company, Gas Cooker Company, Electrical Appliance Company}

In this section, three projects executed by Productivity and Quality Improvement Center are described. 
1) Egyptian Carpet Company: The Company implemented quality control system in 2007 under the supervision of Productivity and Quality Improvement Center. In the company, the meeting was held weekly to improve quality and productivity. At the meeting, it was discussed the cause of failure and the initiatives for reducing defects. At the result, the ratio of defects decreased from $20-23 \%$ before the initiative to $10 \%$ after the initiatives.

2) Gas Cooker Company: In the factory of this company, there were observed in six aspects, as follows. 1) Workers were working very hard and their motion was very speedy, 2) Excessive tasks in the processes were observed, 3) A lot of "MUDAs (wastes)" were observed in material handling and work motion, 4) Assembly shop and press shop were so remotely placed that long distance transportation could be caused, 5) There was almost no safety control system in the pre-treatment process before painting, and 6) There were almost no arrangements in every work places and at material/parts depositories.

Hence Productivity and Quality Improvement Center indicated reducing total production time by eliminating wastes in the process. At the result, 55 hours pre a month were saved.

3) Electrical Appliance Company: Productivity and Quality Improvement Center indicated that the defrost factory included lots of wastes in the subassemble line for defrost refrigerators, for example, there were cluttered work in process at different areas, excessive sello-tapes like 40 times on the ceiling and 52 times in the freezer, difficulty in extracting the condensation tubes, wastes of motion, transportation, waiting and processing (random stand and sitting), no 5s - Sorting, Setting-in-Order, Shining, Standardizing and Sustaining - awareness among workers, and no effective use of the space.

Hence Productivity and Quality Improvement Center proposed six solutions to eliminate these wastes and supervised them in the work place.

At the result, the company succeeded in increasing work efficiency for all workers, ergonomically designed work (eliminating of painful work for workers), eliminating unnecessary workers' motion to bring parts and tools, and eliminating storing-parts in cartoon boxes on the floor. The company eventually reduced two hours per shift.

\section{Service Process}

In general, Productivity and Quality Improvement Center provides their service, as follows;

\section{1) Presentation for Company Executives:}

First of all, in general, Kaizen activities such as QC Circle are familiar for executives in Egyptian companies, however Productivity and Quality Center usually explains general Kaizen methods and their own service for getting trust from company executives. Some explanations and proposal are conducted in Arabic language, but some explanations and proposal are conducted in English. At the cultural point of view, the executives in famous and proven companies have self-confidence, and it is sometimes effective Productivity and Quality Improvement Center to conduct their explanation and proposal in English for large and proven companies to get trust from the executives - when Productivity and Quality Improvement Center presents the methodologies and service in English, the executives tend to recognize they have enough knowledge about the methodologies.

2) Training: Kaizen activities such as QC Circle are not so familiar for the workers in Egyptian Companies, so Productivity 
and Quality Improvement Center provides a few trainings in Arabic. These trainings often used to be supported by the experts in Japan International Corporation Agency. And then, the workshop where the attendees practice to use Kaizen methodology is held under the supervision of Productivity and Quality Improvement Center. This is a trial of QC Circle activity. In this time, engineers who graduated from faculty of engineering in university, and technicians who are working in factory but did not graduate from faculty of engineering are separated into different teams. At the cultural point of view, engineers seems to be superior to technicians, so if the mixture teams for the workshop are built, only engineers tend to address the opinions, on the other hand technicians tend to be silent.

3) Consulting: Consulting activities are conducted by six steps, as follows;

a) Social Occasion Activities: Egyptian workers in the factory, in general, dislike to be pointed out their defects, thus they are often so conservative to change that they tend not to corporate with the professional consultants. The professional consultants, however, investigate the shop floors in the factories with assistance of the workers. To close the mental distance between the workers and the consultants, the consultants sometimes make effort such as making frequent telephone call and spending a social occasion even when it is on holidays. Though these efforts, the consultants can get trusts from the workers.

b) Investigation: In addition to getting trusts from the workers in the factories, the consultants investigate the problem and issues with assistance of the workers.

c) Proposal to Solve the Problem and Issues: After the investigation, the consultants make a report and solution proposal for the executives, and then make a presentation for executives with discussion.

d) Solution Installation: After the approval of the executive, the consultants install the solution into the shop floors in the factories. When they install the solution, they themselves do presentation for the workers and sometimes make prototyping for them, never leaving the workers to improve by themselves. In other word, the consultants work with the workers together until they understand the new process/operations at the shop floors in the factories - this is called "Genchi Genbutsu" in Japanese.

e) QC Circles Activities Activation: At the same time, QC Circle activities are also started in the company to activate the new process installed by the consultants.

f) Evaluation and Circulatalization: After activation of the proposed new process and QC Circle activities, the consultants not always but sometimes visit the factory to evaluate whether the new process and QC Circle activities are effective or not with measures. In case that the proposed solutions are not effective, the consultants propose other options. In case that the proposed solutions are effective to get good results, the consultants elaborate new Kaizen activities with the QC Circle.

\section{Discussion}

Based on the case study, author discusses three aspects related with the research interests in this chapter, as follows: A) How] did Productivity and Quality Improvement Center acquire the know-how Knowledge about Kaizen? , B) How did the customer do the QC Circle activities with the support of Productivity and Quality Improvement 
Center? , C) What are the key factors for success both in of Productivity and Quality Improvement Center and their customer?

A. How did Productivity and Quality Improvement Center acquire the knowhow Knowledge about Kaizen?

To discuss this question, author applies SECI model to interpret the case study.

First of all, before Productivity and Quality Improvement Center was officially established, the chair person in the technical centers under the technological development sector, Ministry of Trade and Industry in Egypt investigates several management methods and suitability of them for Egyptian companies (Miyaji, 2012). Then Kaizen method was tacitly recognized to be suitable for Egyptian companies. This is Socialization process in SECI model.

Second, Productivity and Quality Improvement Center was officially established and learnt Kaizen to provide the service with support by the Japanese Kaizen experts in Japan International Corporation Agency. This is Externalization in SECI model.

However, as the executive manager in Productivity and Quality Improvement
Center mentioned, the mentality of Egyptian workers are different from Japanese worker like segregation of engineers and technician. Based upon such knowledge of Egyptian consultants, QC Circle activities were localized in order to suite for the Egyptian culture. For example, engineers who graduated from faculty of engineering in university, and technicians who are working in factory but did not graduate from faculty of engineering are separated into different teams, although all of the section member from manager to worker join one team in case of the QC Circle in Japan. And the Egyptian consultants in Productivity and Quality Improvement Center often contacts with Egyptian workers over phone and spend time with them even when it is on holidays to make a mutual trust between the consultants and the workers. This is Combination process in SECI model.

Finally, the Egyptian consultants in Productivity and Quality Improvement Center continue to support the QC Circle activities, and then gradually became able to provide the services by themselves. This is Internalization process in SECI model.

This SECI model in Productivity and Quality Improvement Center is shown in Figure 1.

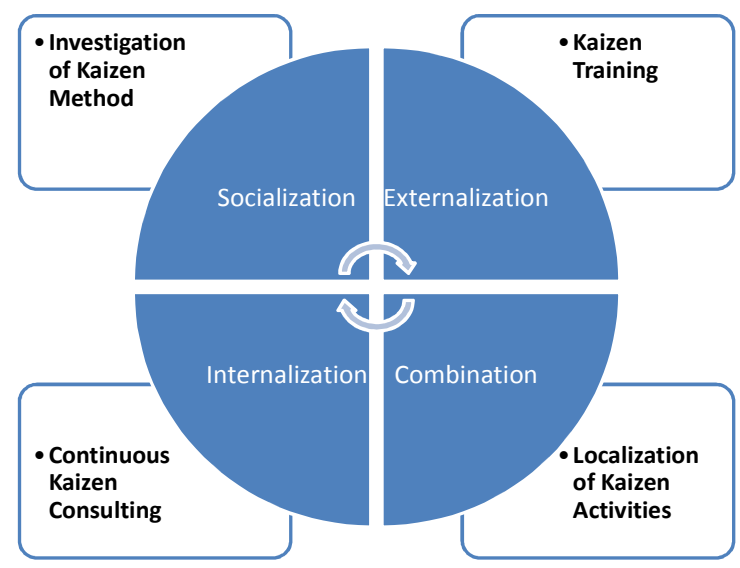

Figure 1: SECI model in Productivity and Quality Improvement Center 
B. How did the customer succeed in the $Q C$ Circle activities with the support of Productivity and Quality Improvement Center?

To discuss this question, author applies five stages model in enterprise transformation (Liu, Nagayoshi and Iijima, 2012) to interpret the case study. Stage 0 is one in which old dominant logic is running. Stage 1 is one in which organization is preparing for transformation. Stage 2 is one in which organization adds new logic. Stage 3 is one in which organization is changing dominant logic. Stage 4 is one in which new dominant logic is running.

Customers of Productivity and Quality Improvement Center ran their business/process with wastes before Kaizen activities. This is Stage 0 in five stages model. The executives of the customer have some knowledge about Kaizen. Productivity and Quality Improvement Center explains and proposes Kaizen project, and then the executives are enthusiastic to dedicate themselves to Kaizen project. This is Stage 1 in five stages model.
Then, Productivity and Quality Improvement Center provides training course in order for workers to acquire the knowledge about Kaizen and related tools. This is Stage 2 in five stages model.

After the training, Productivity and Quality Improvement Center provides consulting service in order to improve the business process, eliminate wastes, and install QC Circle in the customer companies. This is Stage 3 in five stages model.

Finally, the customer companies improve their productivity and quality, in addition Productivity and Quality Improvement Center indicates the customer companies to continue Kaizen activities such as QC Circle activities, and the customer companies do so by themselves with small assistance of Productivity and Quality Improvement Center. This is Stage 4 in five stages model.

These five stages for enterprise innovation in Egyptian companies consulted by Productivity and Quality Improvement Center are shown in Figure 2.

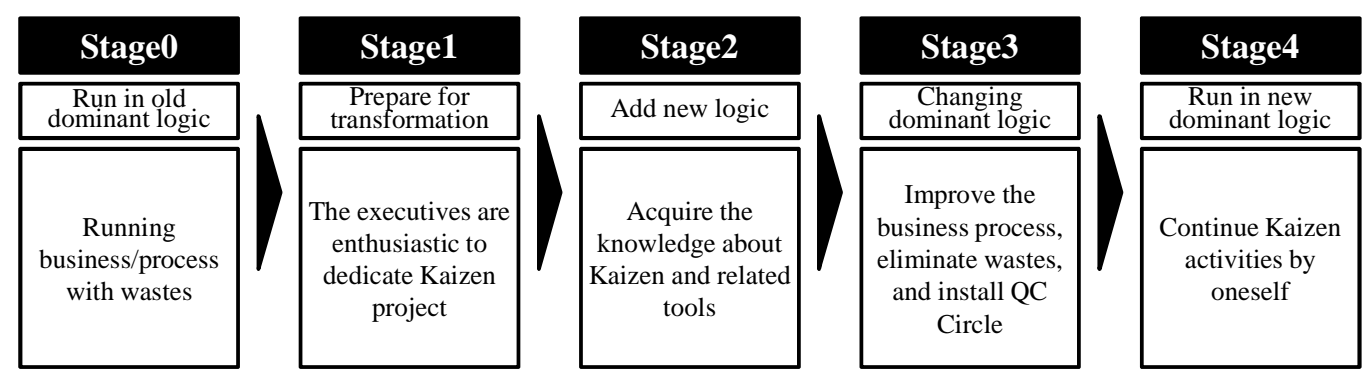

Figure 2: Five Stages for Enterprise Innovation in Egyptian Companies

C. What are the key factors for success both in of Productivity and Quality Improvement Center and their customer?

1) Why was Kaizen Selected in Egypt?: Traditionally Egypt has been affected by Western countries to apply their management methods such as six sigma, but these are too advanced management method for Egyptian companies which does not establish essential manners to use well. On the other hand, Kaizen activities such as QC Circle activities are so essential that Egyptian company can easily use and execute it.

2) Segregation of Engineers and Technicians: From the cultural back ground, engineers who graduated from the faculty of engineering in university 
and technicians who did not graduate from the faculty of engineering in university have curious mentality. In general engineers seem to be superior to technician, although technicians are also skillful. Sometimes QC Circle activities do not step forward, when they do QC Circle activities together. Hence Productivity and Quality Improvement Center usually makes an arrangement to separate engineer from technician for the sake of their active discussion in QC Circle activities. In case that the two groups make different idea, Productivity and Quality Improvement Center play a bridge role between the two groups. These arrangements are supposed to be one of the key success factors for executing Kaizen activities in Egypt.

3) Mutual Trust Building: From the cultural back ground, company workers tend not to easily trust each other. Such tendency is more for the outside professionals. In general workers usually tend not to disclose the status in the company to prevent them from being pointed out the defects related to them. To build up mutual trust between the workers and the professional consultants in Productivity and Quality Improvement Center, the professional consultants often make a phone call and visit, and sometimes spend the time with workers even when it is on holidays. These arrangements are also supposed to be one of the key success factors for executing Kaizen activities in Egypt, although it seems to be one of the most important factors to build mutual trust all over the world.

4) Hands-On Support in the Shop Floor: Some professional consulting firms provide training courses and reports as a consulting service. Unfortunately few Egyptian companies, however, have enough knowledge and/or skills to execute the initiatives by themselves, which are taught and/or proposed by the professional consulting firms. Hence Productivity and Quality Improvement
Center provides not only training and reports for solving issues and/or problems but also hands-on supervision in the factory shop floor. The professional consultants transfer their know-how knowledge to the workers, and sometimes make prototypes with the workers. These arrangements are also supposed to be one of the key success factors for executing Kaizen activities in Egypt.

\section{Implication}

As a professional consulting firm, Productivity and Quality Improvement Center provides not only training and reports for solving issues and/or problems but also hands-on supervision in the factory shop floor.

Based on author's experience in a certain global professional consulting firm, there are a couple types of consulting services, as follows.

\section{A. Consider 'SOLUTION' with Customer}

In this type, professional consultants indicate the solution with customer.

This type of service is sometimes prepared apart from customer site. For example, when customer needs ideas for their new business and/or customer needs case studies for creating their own management systems, professional consultants provide reports for finding the solution and/or discuss the solution at customers' office a few times a week based on the discussion papers which the professional consultants prepare at our office.

This type of service is sometimes provided on customer site. For example, when consultants create the solution as a member of the customers' company worker, the professional consultants stay at customers' office every day and discuss the solution with executives at any time. Based on author's experience, the professional consultants generally get high customer satisfaction 
when they provide the service in this way. The professional consultants in Productivity and Quality Improvement Center take this way.

\section{B. Do Everything on of Behalf of Company Staff}

In this type, professional consultants work on behalf of worker on customer site.

For example, when there are too many issues for the executives to consider the important issues and/or the executives are too busy to solve the issues/problems but there are not enough skills within the company staff, professional consultants offer everything but decision making like staying at customers' office every day, creating new idea proposal papers, doing facilitation in the business meeting, and making presentation on behalf of company staff.

\section{Teaching, Coaching and Investigator}

In this type, this type of service is sometimes prepared apart from customer site. For example, when customer needs research reports at the comprehensive and neutral point of view, professional consultants make research reports based upon their own research and their experience.

Also professional consultants sometimes provide lecture and/or coaching service as a discussion counterpart on customer site when the customer needs them.

Based on author's experience, professional consultant cannot easily get high customer satisfaction, and it is also difficult to get a continuous engagement. Hence Productivity and Quality Improvement Center is supposed to provide not only training service as a lecture but also on-site type of consulting service.

These consulting delivery types are shown in Table1. 
Table 1: Consulting Delivery Types

\begin{tabular}{|c|c|c|c|c|}
\hline \multirow[b]{2}{*}{ Type } & \multicolumn{4}{|c|}{ Professional Consultants' Work } \\
\hline & Main Task(s) & Example & Delivery & $\begin{array}{c}\text { Customer } \\
\text { Satisfaction }\end{array}$ \\
\hline \multirow[b]{2}{*}{$\begin{array}{l}\text { Consider solution } \\
\text { with customer }\end{array}$} & $\begin{array}{l}\text { - Making report(s) } \\
\text { - Discussion on the } \\
\text { solution at customers' } \\
\text { office }\end{array}$ & $\begin{array}{l}\text { Customer needs } \\
\text { ideas for and } \\
\text { case studies new } \\
\text { business }\end{array}$ & Off-site & middle \\
\hline & $\begin{array}{l}\text { Discuss the } \\
\text { solution with } \\
\text { executives at any time }\end{array}$ & $\begin{array}{l}\text { Consultants } \\
\text { work as a } \\
\text { member of the } \\
\text { customers' } \\
\text { company } \\
\text { workers }\end{array}$ & On-site & high \\
\hline $\begin{array}{l}\text { Do everything on } \\
\text { behalf of company } \\
\text { staff }\end{array}$ & $\begin{array}{l}\text { - Consultant offer } \\
\text { everything on behalf } \\
\text { of the company staff }\end{array}$ & $\begin{array}{l}\text { In case of } \\
\text { overload of } \\
\text { executive and/or } \\
\text { lack of adequate } \\
\text { skills in staff }\end{array}$ & On-site & high \\
\hline \multirow{2}{*}{$\begin{array}{l}\text { Teaching, Coaching } \\
\text { and Investigator }\end{array}$} & $\begin{array}{l}\text { Making research } \\
\text { reports based upon } \\
\text { the investigation } \\
\text { and/or experience }\end{array}$ & $\begin{array}{l}\text { Customer needs } \\
\text { research reports } \\
\text { from } \\
\text { comprehensive } \\
\text { and neutral point }\end{array}$ & Off-site & \multirow{2}{*}{ middle -low } \\
\hline & $\begin{array}{l}\quad \text { Providing lecture } \\
\text { and/or coaching } \\
\text { service as a discussion } \\
\text { counterpart on } \\
\text { customer site }\end{array}$ & $\begin{array}{l}\text { Whenever the } \\
\text { customer needs } \\
\text { professional } \\
\text { consultant }\end{array}$ & On-site & \\
\hline
\end{tabular}

\section{Conclusion}

In this paper, author discussed three topics based upon the case study in Productivity and Quality Improvement Center in Egypt. First it is supposed that Productivity and Quality Improvement Center acquired the Know-How knowledge of Kaizen method in the accordance with SECI model. Second, the customer company of Productivity and Quality Improvement Center in Egypt is supposed to transform their business in the accordance with the five stages model. Finally, the key factors for success in Kaizen initiatives were discussed at the both of Productivity and Quality Improvement Center and their customer points of view.
To my best knowledge, there are few numbers of researches as to organizational change and transformation in Arab world. These findings suggest that it is fruitful for academic researchers to dedicate themselves to further study the organizational change and transformation in Arab world.

This study is qualitative and it is necessary to collect more quantitative evidence to further support the findings. To this end, it is also necessary to develop quantitative indicators. More studies are needed to generalize the findings beyond this study. 


\section{Acknowledgement}

The author thanks Mr. Ayman Aly Deghaidy Executive Manager, Mr. Mohamed Emam Atta - Head of Training Section, and Mr. Amr Mostafa Haroun - Head of Consulting Section in Productivity and Quality Improvement Center, who kindly dedicated time to our research work. We could not achieve our work without their generous cooperation.

\section{References}

Ayano, K. (2009). 'QC Circle Activities: Literature Review of QC Circle Activities Abroad,' Quality, Vol. 39(2), 35-41.

Deming, W. E. (1996). 'The New Economics for Industry, Government, Education (2nd Edition),' NTT Publisher.

Dessus, S. \& Suwa-Eisenmann, A. (1998). Trade Integration with Europe, Export Diversification and Economic Growth in Egypt, OECD Development Center.

Eisenhardt, K. M. (1989). "Building Theories from Case Study Research," Academy of Management Review, Vol. 14 (4), 532-550.

Enkawa, T. (2009). 'Japanese Culture and Quality. Its Source and Future Perspective,' JSA Press.

Enkawa, T. (2010). 'A Cultural Perspective on Japanese Strength and Weakness in Operations Management,' Journal of Japan Industrial Management Association, Vol. 61, 131-138.

Fiol, C. M. \& Lyles, M. A. (1985). "Organizational Learning," Academy of Management Review, Vol. 10 (4), 803-813.

Florida, R. (2005). 'The Flight of the Creative Class,' Harper Collins Publishers.

Honda, S. \& Noguchi, H. (2004). 'Program Based Approach in Asian Countries,' International Corporation Research, Vol. 40.
Liu, Y., Nagayoshi, S. \& Iijima, J. (2012). 'Innovative Transformation in a Knowledge Intensive Industry: A Case Study of an Organizational Learning Based Enterprise,' International Conference on Proceedings on International Conference on Inclusive Innovation and Innovative Management 2012. December 14-15, 2012. Bangkok, Thailand. 190-198.

Mabuchi, S. \& Kuwajima, K. (2004). 'Capacity Development and Effective Corporation in Developing Countries,' International Corporation Research, Vol. 39.

Miyaji,T. (2012). 'Productivity and Quality Improvement Center in Egypt and Productivity in South Africa,' Academy of Management Review, Vol. 11 (19), Global Research Center, 703-712.

Nonaka, I. \& Takeuchi, H. (1995). 'The Knowledge-Creating Company: How Japanese Companies Create the Dynamics of Innovation,' Oxford University Press, New York.

Slater, S. F. \& Narver, J. C. (1995). "Market Orientation and the Learning Organization," Journal of Marketing, Vol. 59 (3), 63-74.

The World Bank (2013). World Data Indicator, [Online], [Retrieved March 1, 2013], http://www.worldbank.org/

World Health Organization (2012). World Health Statistics 2012. 